\title{
Effect of patient socioeconomic status on perceptions of first- and second-year medical students
}

\author{
James K.H. Woo, Sahar H. Ghorayeb, Cheong K. Lee, Harpreet Sangha, Suzanne Richter
}

ß See related article page 1920

Abstract

Background: Physician decision-making and perceptions of patients are affected by a patient's socioeconomic status (SES). We sought to determine if the perceptions of first- and secondyear medical students are similarly affected. We also wanted to determine whether a student's own SES affects his or her perceptions of patients from a low or high SES background.

Methods: Two similar videos of a physician-patient interview were created. One video featured a patient of apparently high SES and the other featured a patient of apparently low SES. Differences in SES were portrayed by means of clothing, accessories and dialogue. First- and second-year medical students at the University of Western Ontario were recruited to view 1 of the videos and to answer a questionnaire using a 5point Likert scale.

Results: Responses were obtained from 205 (89\%) of the 231 medical students invited to participate. Respondents' perceptions of the low SES and high SES patients were significantly different in the following respects. The low SES patient was perceived to be less compliant in taking medications and less likely to return for follow-up visits; was perceived to have a lower level of social support, poorer overall health and a worse prognosis; and was perceived to be more adversely affected in his occupational duties by illness $(p<0.05)$. Furthermore, second-year students who watched the video with the low SES patient were less inclined to want that patient in their practice than second-year students who watched the video with the high SES patient $(p=0.032)$. One hundred and six students (52\%) were categorized as having high SES and $37(18 \%)$ as having low SES (the remaining students were categorized as having mid-level SES). Among students who watched the video with the low SES patient, the level of agreement with the statement "This person is the kind of patient I would like to have in my practice" was greater among low SES students than among high SES students $(p=0.012)$.

Interpretation: First- and second-year medical students have negative perceptions of low SES patients on several dimensions.

I $\mathrm{n}$ spite of the fact that Canada has a universal and accessible health care system, Canadians experience disparities in the delivery of health care according to their income level. ${ }^{1-4}$ Physicians' perceptions of their patients can be influenced by the patients' socioeconomic status (SES), and in turn these perceptions affect the health care that the physicians provide. ${ }^{5,6}$ Previous studies have emphasized the need to understand the origins of such perceptions. Using a video portraying a typical physician-patient interview and a survey administered to first- and second-year medical students, we examined students' perceptions of patients from different socioeconomic backgrounds. Our hypothesis was that medical students would have negative perceptions of low SES patients. Furthermore, we wished to determine whether any differences in perception existed between first- and second-year medical students and between students with low and high SES.

\section{Methods}

Two videos depicting a physician-patient interview, one with a low SES patient and the other with a high SES patient, were filmed. The roles of physician and patient were played by 2 professional male actors hired by the University of Western Ontario (UWO) Standardized Patient Program. One actor played the role of the physician in both videos, and the other actor played the roles of both the low SES patient and the high SES patient. The scripts in the 2 videos were similar, differing only in terms of some of the patient responses (Box 1). Differences in the patients' apparent SES were shown through clothing, hygiene, accessories, language and script (Fig. 1, Table 1). The videos can be viewed online at www.cmaj.ca/cgi/content/full/170/13/1915/DC1.

With the help of 6 other students, we developed a survey that used bipolar 5-point Likert rating scales to capture student responses, with 1 representing the negative extreme (e.g., noncompliant) and 5 representing the positive extreme (e.g., extremely compliant). Ethics approval was obtained from the UWO Research Ethics Board.

First- and second-year UWO medical students were recruited for and participated in the study on Apr. 9 and 14, 2003, respectively, during patient-centred learning (PCL) course time. Each PCL group of 8 students was predetermined before the study by the Undergraduate Medical Education (UME) office. Assignment to PCL groups was not completely random: the UME office attempted to ensure approximately equal numbers of male and female students in each PCL group. Students in even-numbered PCL groups viewed the video with the low SES patient and those in odd-numbered PCL groups viewed the video with the high SES patient. No incentives were given to students, participation in the study was voluntary and in- 
formed consent was obtained. Students were not aware that perceptions of patient SES were being measured. After presentation of the video, each student completed the survey. Students were asked to keep their knowledge of the study confidential until Apr. 15, 2003.

Two-sample independent $t$ tests were used to compare responses between students who viewed the low SES video and those who viewed the high SES video (within each medical

\section{Box 1: Excerpts from scripts used in videos with} patients of high and low socioeconomic status

\section{D: Does your spouse work?}

$\mathrm{H}$ : She's a high school teacher.

L: Yeah, she's a sales clerk down at the Bay.

D: What do you do?

$\mathrm{H}$ : I'm a partner at a law firm in downtown London, right near the corner of Richmond and Dundas.

L: I work at a convenience store in downtown London, right by Richmond and Dundas.

D: And when did these chest pains first begin?

$\mathrm{H}$ : I first noticed them when I was on the driving range 2 weeks ago.

L: Well, I first noticed the pain while I was washing my truck 2 weeks ago.

D: Do you remember if there were any complications involved with your birth?

H: No. As a matter of fact, my mother always said that the birth went free and easy.

L: No. My mom has always said I was the easiest birth she had. She had 6 kids.

D: How much would you say you drink in a week?

$\mathrm{H}$ : I have 1 or 2 single malt scotches 3 times a week or so when I'm out for dinner with clients.

$\mathrm{L}$ : A couple of bottles of Coors, a couple of times a week, usually when I'm watching wrestling.

D: Okay. Obviously, this chest pain is having a definite impact on your life, especially in terms of work. However, based on your history, I'm not quite sure as to the cause of your chest pain so I'm going to schedule you in for some tests this afternoon.

$\mathrm{H}$ (consults personal digital assistant): I've got an important meeting with an important client this afternoon. It's going to be pretty difficult.

$\mathrm{L}$ (consults loose-leaf page): Uhhh, I'm working a shift this afternoon. Johnny's not going to like it if I phone in sick again.

D: Okay. I might need to prescribe some medication for you after I see the results from the test. Do you have a drug plan?

$\mathrm{H}$ : Yes, my firm supplies one.

$\mathrm{L}$ : Yeah, my wife's got one from work.

$\mathrm{D}=$ doctor, $\mathrm{H}=$ patient with high socioeconomic status $\mathrm{L}=$ patient with low socioeconomic status. school year). Surveys were also grouped according to students' self-reported gross family income, with low SES defined as family income less than \$61 000 and high SES defined as family income greater than $\$ 100$ 999; students with a self-reported gross family income between $\$ 61000$ and $\$ 100999$ were excluded from this particular analysis. The responses of low and high SES students were compared with 2 -sample independent $t$ tests for each video.

\section{Results}

Responses were obtained from 205 (89\%) of the 231 medical students invited to participate. Of these, 48 (23\% of the total) and $58(28 \%)$ first-year students watched the high and low SES videos respectively, while $52(25 \%)$ and $47(23 \%)$ second-year students watched the high and low SES videos respectively. Student characteristics are presented in Table 2. Although no significant difference in gross family income was detected for first-year students, first-year students who watched the high SES video considered themselves to be of a higher socioeconomic class than those who watched the low SES video $(p=0.042)$. First-year students who watched the low SES video were significantly older (by a mean of 8 months) than first-year students who watched the high SES video $(p=0.015)$.

Both first- and second-year students perceived that the low SES patient would be less compliant in taking his medications ( $p<0.001$ and $p=0.001$ respectively), would be less likely to come in for monthly follow-up $(p=0.004$ and $p=0.033$ respectively) and would have a lower level of social support ( $p<0.001$ for both groups) than the high SES patient (Table 3). Among both first- and sec-

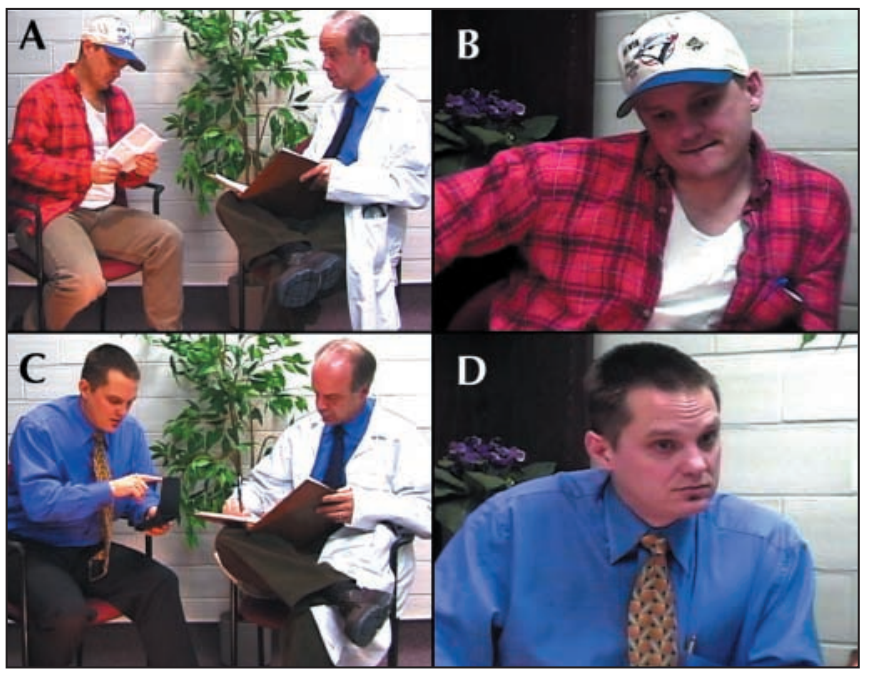

Fig. 1: (a) Still from the video with the patient of low socioeconomic status (SES), showing both patient and physician; (b) close-up of low SES patient; (c) still from the video with the high SES patient, showing both patient and physician; (d) close-up of high SES patient. 
ond-year students, there was no significant difference between those who watched the low SES video and those who watched the high SES video in perception of the patient's truthfulness about his drinking habits. Students in both years identified the patient in the low SES video as having low SES and the patient in the high SES video as having high SES $(p<0.001)$, which confirmed that a difference in SES was apparent.

With further analysis, 106 (52\%) and 37 (18\%) surveys were categorized as representing responses of high and low SES students respectively (data not shown). Low SES students perceived that the high SES patient was less likely to come in for a monthly follow-up $(p=0.049)$. Among students who watched the video with the low SES patient, the level of agreement with the statement "This person is the kind of patient I would like to have in my practice" was greater among low SES students than among high SES students $(p=0.012)$.

\begin{tabular}{|c|c|c|}
\hline Aspect of portrayal & High SES patient & Low SES patient \\
\hline Accessories & $\begin{array}{l}\text { Personal digital assistant, expensive-looking } \\
\text { watch, expensive-looking pen in shirt pocket }\end{array}$ & Loose-leaf paper, Bic pen in shirt pocket \\
\hline $\begin{array}{l}\text { Activity that precipitated } \\
\text { chest pain }\end{array}$ & Golfing (at driving range) & Washing truck \\
\hline $\begin{array}{l}\text { Activity while consuming } \\
\text { alcohol }\end{array}$ & Dinner with clients & Watching wrestling on TV \\
\hline Choice of alcoholic drink & Single malt scotch & Beer \\
\hline Clothing & Dress shirt, tie, dress pants & $\begin{array}{l}\text { Baseball cap, lumberjack shirt, white } \\
\text { undershirt, corduroy pants, black boots }\end{array}$ \\
\hline Hygiene & Shaved & Stubble \\
\hline Occupation & Partner in law firm & Clerk at convenience store \\
\hline Use of language & See Box 1 & See Box 1 \\
\hline
\end{tabular}

Table 2: Characteristics of medical students at the University of Western Ontario participating in the study*

\begin{tabular}{|c|c|c|c|c|}
\hline \multirow[b]{2}{*}{ Characteristic } & \multicolumn{2}{|c|}{ First-year students } & \multicolumn{2}{|c|}{ Second-year students } \\
\hline & $\begin{array}{c}\text { Video with high } \\
\text { SES patient } \\
n=48\end{array}$ & $\begin{array}{l}\text { Video with low } \\
\text { SES patient } \\
n=58\end{array}$ & $\begin{array}{l}\text { Video with high } \\
\text { SES patient } \\
n=52\end{array}$ & $\begin{array}{c}\text { Video with low } \\
\text { SES patient } \\
n=47\end{array}$ \\
\hline Sex, no. (and \%) of men & $25+(52)$ & $32 \dagger(55)$ & $23(44)$ & $23(49)$ \\
\hline Mean age (and SD), yr & $22.77 \quad(1.42)$ & $23.45 \quad(1.40)$ & $24.27(1.23)$ & $24.26(0.95)$ \\
\hline \multicolumn{5}{|c|}{ Estimated gross annual family income, $\$ \ddagger$} \\
\hline$<30000$ & $(2)$ & $(2)$ & 0 & $2 \quad(4)$ \\
\hline 30000 to 60999 & $5 \quad(10)$ & $9 \quad(16)$ & $10(19)$ & $9(20)$ \\
\hline 61000 to 100999 & 12 (25) & $22 \quad(38)$ & $14(27)$ & $14(30)$ \\
\hline 101000 to 200000 & $22 \quad(46)$ & $19 \quad(33)$ & $17(33)$ & $17(37)$ \\
\hline$>200000$ & $8 \quad(17)$ & $7 \quad(12)$ & $11(21)$ & $4 \quad(9)$ \\
\hline \multicolumn{5}{|l|}{ Perception of family's social class } \\
\hline Lower class & 0 & 0 & 0 & $1 \quad(2)$ \\
\hline Between lower and middle class & $(4)$ & (9) & $2(4)$ & $3(6)$ \\
\hline Middle class & $16 \quad(33)$ & 28 & $27(52)$ & $21(45)$ \\
\hline Between middle and upper class & $28 \quad(58)$ & $24 \quad(41)$ & $20(38)$ & $20(43)$ \\
\hline Upper class & (4) & $1 \quad(2)$ & $3 \quad(6)$ & $2 \quad(4)$ \\
\hline \multicolumn{5}{|l|}{ Population of home town $¥$} \\
\hline$<5000$ & $(6)$ & $6 \quad(10)$ & 2 (4) & $5(11)$ \\
\hline 5000 to 30999 & $(4)$ & $4 \quad(7)$ & $7(13)$ & $4 \quad(9)$ \\
\hline 31000 to 100999 & (19) & $9 \quad(16)$ & $5(10)$ & $4 \quad(9)$ \\
\hline 101000 to 500000 & $12 \quad(25)$ & 17 (29) & $20(38)$ & $13(28)$ \\
\hline$>500000$ & $22 \quad(46)$ & 22 (38) & $18(35)$ & $20(43)$ \\
\hline
\end{tabular}

*Data are presented as no. (and \%) of students, unless indicated otherwise.

†Actual data were not available; these values are approximations.

fData missing for 1 second-year student who viewed the video with the low SES patient. 


\section{Interpretation}

To our knowledge, medical students' perceptions of high and low SES patients have not been evaluated in any substantial published study. Our results support the hypothesis that medical students have negative perceptions of low SES patients. The low SES patient was perceived to be less compliant; to have less social support, poorer overall health and a poorer prognosis; and to be more adversely affected with respect to his occupational duties than the high SES patient. Furthermore, second-year students and high SES students showed a greater preference to have the high SES patient in their practice rather than the low SES patient. Overall, second-year students had negative perceptions of low SES patients on a greater number of dimensions than first-year students.

These medical students' perceptions mirror some of the perceptions that other investigators have found among physi- cians. For example, van Ryn and Burke ${ }^{6}$ demonstrated that physicians are more likely to perceive low SES patients as being less intelligent, independent, responsible, rational, physically active and compliant and as having less significant career demands than high SES patients. In a study of general practitioner decision-making, Scott and associates ${ }^{5}$ found that diagnostic tests were less likely to be ordered for low SES patients than for high SES patients and that low SES patients were more likely to receive a prescription. However, patient SES was not associated with a physician's decision to follow up. In our study of medical students, patient SES was not significantly associated with the decision to refer to a specialist.

The parental income of the UWO first- and secondyear classes was similar to that of other Canadian medical school classes, ${ }^{7}$ in that students from high-income families were overrepresented and students from low-income families were underrepresented. Our results suggest that low SES students would prefer low SES patients in their prac-

Table 3: Medical students' perceptions of the high SES patient and low SES patient*

\begin{tabular}{|c|c|c|c|c|c|c|}
\hline \multirow[b]{2}{*}{ Student's perception } & \multicolumn{3}{|c|}{ First-year students } & \multicolumn{3}{|c|}{ Second-year students } \\
\hline & $\begin{array}{l}\text { Video with high } \\
\text { SES patient } \\
\quad n=48\end{array}$ & $\begin{array}{l}\text { Video with low } \\
\text { SES patient } \\
\quad n=58\end{array}$ & $p$ valuet & $\begin{array}{l}\text { Video with high } \\
\text { SES patient } \\
\quad n=52\end{array}$ & $\begin{array}{l}\text { Video with low } \\
\text { SES patient } \\
\quad n=47\end{array}$ & $p$ value \\
\hline \multicolumn{7}{|l|}{ Perceived patient behaviours and abilities } \\
\hline $\begin{array}{l}\text { Patient's understanding of his medical problem }(1=\text { no } \\
\text { understanding, } 5=\text { complete understanding })\end{array}$ & $2.2(0.6)$ & $2.0(0.6)$ & 0.23 & $2.1(0.6)$ & $1.8(0.7)$ & 0.11 \\
\hline $\begin{array}{l}\text { Compliance with medications }(1=\text { noncompliant, } \\
5 \text { = fully compliant) }\end{array}$ & $3.8(0.8)$ & $3.0(0.8)$ & $<0.001$ & $3.3(0.8)$ & $2.7(0.9)$ & 0.001 \\
\hline $\begin{array}{l}\text { Likelihood of monthly follow-up }(1=\text { not likely, } \\
5=\text { extremely likely) }\end{array}$ & $3.0(1.1)$ & $2.4(0.9)$ & 0.004 & $2.9(1.0)$ & $2.4(1.0)$ & 0.033 \\
\hline $\begin{array}{l}\text { Level of social support ( } 1=\text { no support, } 5=\text { complete } \\
\text { support) }\end{array}$ & $3.8(0.7)$ & $3.1(0.8)$ & $<0.001$ & $3.6(0.6)$ & $3.1(0.6)$ & $<0.001$ \\
\hline $\begin{array}{l}\text { Patient's truthfulness about his drinking, } \\
\chi^{2} \text { (and degrees of freedom) } \neq\end{array}$ & \multicolumn{2}{|c|}{$0.201(1)$} & 0.65 & \multicolumn{2}{|c|}{$1.456(1)$} & 0.48 \\
\hline $\begin{array}{l}\text { Effect of condition on ability to do job ( } 1=\text { no effect, } \\
5=\text { strong effect) }\end{array}$ & $3.3(0.8)$ & $3.5(0.8)$ & 0.21 & $3.1(0.8)$ & $3.7(0.8)$ & $<0.001$ \\
\hline \multicolumn{7}{|l|}{ Perceptions of the patient's disease } \\
\hline Prognosis ( 1 = not good, 5 = extremely good) & $3.4(0.6)$ & $3.3(0.8)$ & 0.51 & $3.5(0.7)$ & $3.2(0.8)$ & 0.036 \\
\hline $\begin{array}{l}\text { Severity of disease ( } 1=\text { not severe, } 5=\text { extremely } \\
\text { severe) }\end{array}$ & $3.0(0.7)$ & $3.0(0.6)$ & 0.96 & $2.9(0.6)$ & $3.0(0.6)$ & 0.46 \\
\hline Overall health ( 1 = extremely poor, 5 = excellent) & $3.2(0.7)$ & $2.9(0.7)$ & 0.035 & $3.3(0.6)$ & $3.1(0.6)$ & 0.18 \\
\hline $\begin{array}{l}\text { Discomfort or inconvenience related to chest pain } \\
\text { ( } 1=\text { no discomfort, } 5=\text { extreme discomfort })\end{array}$ & $3.4(0.5)$ & $3.3(0.6)$ & 0.18 & $3.1(0.6)$ & $3.3(0.7)$ & 0.15 \\
\hline $\begin{array}{l}\text { Likelihood of sending patient for a second opinion or } \\
\text { to a specialist ( } 1=\text { not likely, } 5=\text { extremely likely) }\end{array}$ & $3.5(1.1)$ & $3.4(1.0)$ & 0.90 & $3.2(1.1)$ & $3.2(1.0)$ & 0.89 \\
\hline \multicolumn{7}{|l|}{ Future practice patterns } \\
\hline $\begin{array}{l}\text { "This person is the kind of patient I would like to have } \\
\text { in my practice." ( } 1=\text { completely disagree, } \\
5 \text { = completely agree) }\end{array}$ & $3.7(0.9)$ & $3.6(1.0)$ & 0.51 & $3.8(0.8)$ & $3.4(1.0)$ & 0.032 \\
\hline \multicolumn{7}{|l|}{ Other } \\
\hline $\begin{array}{l}\text { Effect of patient's SES on physician decision-making ( } 1 \\
=\text { no effect, } 5=\text { strong effect) }\end{array}$ & $2.8(1.0)$ & $3.2(0.8)$ & 0.032 & $3.2(0.9)$ & $3.4(0.9)$ & 0.38 \\
\hline $\begin{array}{l}\text { Description of patient's SES ( } 1=\text { very low, } 3=\text { middle, } \\
5=\text { very high) }\end{array}$ & $4.2(0.6)$ & $2.1(0.5)$ & $<0.001$ & $4.1(0.5)$ & $2.2(0.4)$ & $<0.001$ \\
\hline
\end{tabular}


tices more than high SES students would. This finding complements previous work characterizing US physicians who provide high levels of service to underserved populations. ${ }^{8}$ Physicians with low SES backgrounds (low parental income and education) showed significantly higher levels of service to poor patients than physicians with high SES backgrounds, even after adjustment for physician race, ethnic background and sex.

The cause of negative perceptions of low SES patients is unclear. For example, although some studies suggest that lower SES is an independent risk factor for lower compliance and follow-up attendance, ${ }^{9-12}$ others have found either no correlation ${ }^{13,14}$ or greater compliance among low SES patients. ${ }^{15}$ Socioeconomic factors are associated with true patient differences in certain cases. For instance, physicians perceive low SES patients as being less likely to desire a very physically active lifestyle, a perception that is consistent with research findings. ${ }^{6,16-18}$ However, if a physician applies such an epidemiologically supported, populationbased likelihood to an individual patient, without regard for any contradicting evidence for that patient, then the stereotype is not deserved.

Several limitations of this study should be considered. First-year students watching the low SES video were significantly older than those watching the high SES video. The scripts for the 2 videos were similar, but the personality and behavioural mannerisms of the patient varied slightly between videos, which might have had an effect on student responses. The lack of an option such as "There isn't enough information to answer the question" meant that students who wanted more information were forced to choose a response on the 5-point Likert scale that might not have reflected their opinion accurately. Our study was not longitudinal, so any differences between first- and second-year students might have been due to differences in the sample itself, rather than to differences between years of education. The differences detected were subtle (none exceeded 1.0 on the Likert scale) and might not have been clinically significant. Perceptions could vary from encounter to encounter but each student viewed only 1 video; thus, it might be necessary to have subjects view more cases to achieve a more realistic understanding of perceptual differences. First- and second-year medical students do not have a great deal of contact with patients, so their perceptions are not yet shaped by real-world experience. The generalizability of this study may be limited because subjects consisted of UWO medical students only. Finally, the arbitrary lowincome cutoff of $\$ 60999$ would probably not be perceived as a low income by the average Canadian family.

Our results demonstrate that medical students have negative perceptions of low SES patients. More negative perceptions were found among second-year students, but the reason for this difference is unclear. Low SES students had a greater willingness than high SES students to have the low SES patient in their future practice. We have expanded on earlier studies by demonstrating that physicians' negative percep- tions of low SES patients are apparent at an early stage in their training. Delineating the origins of these perceptions is an important avenue of research that needs to be explored.

This article has been peer reviewed.

The authors are medical students at the University of Western Ontario, London, Ont.

Competing interests: None declared.

Contributors: James Woo and Cheong Lee were equally responsible for conceiving the project. James Woo was responsible for coordinating the project. All authors shared the work of collecting and analyzing the data and writing the manuscript.

Acknowledgements: We are grateful to Nina Ghosh, Dmitry Guller, David Huxley, Anna Labuda and Ali Namazie for their assistance in creating the videos and developing and administering the survey, to Judy McCormick and the University of Western Ontario Standardized Patient Program for their support in production of the videos, to Dr. Peter Flanagan for reviewing our proposal and manuscript, to Dr. Jeffrey Nisker for reviewing our proposal, and to Dr. Jacalyn Duffin and Dr. Milton Woo for critically reviewing our manuscript.

\section{References}

1. Alter DA, Naylor CD, Austin P, Tu JV. Effects of socioeconomic status on access to invasive cardiac procedures and on mortality after acute myocardial infarction. N Engl 7 Med 1999;341(18):1359-67.

2. Badgley R, Wolfe S. Equity and health care. In: Naylor C, editor. Canadian bealth care and the state: a century of evolution. Montreal: McGill-Queen's University Press; 1992. p. 193-237.

3. McIsaac W, Goel V, Naylor D. Socio-economic status and visits to physicians by adults in Ontario, Canada. 7 Health Serv Res Pol 1997;2(2):94-102.

4. Katz SJ, Hofer TP. Socioeconomic disparities in preventive care persist despite universal coverage. Breast and cervical cancer screening in Ontario and the United States. FAMA 1994;272(7):530-4.

5. Scott A, Shiell A, King $M$. Is general practitioner decision making associated with patient socio-economic status? Soc Sci Med 1996;42(1):35-46.

6. Van Ryn M, Burke J. The effect of patient race and socio-economic status on physicians' perceptions of patients. Soc Sci Med 2000;50(6):813-28.

7. Dhalla IA, Kwong JC, Streiner DL, Baddour RE, Waddell AE, Johnson IL. Characteristics of first-year students in Canadian medical schools. CMAJ 2002;166(8):1029-35.

8. Cantor JC, Miles EL, Baker LC, Barker DC. Physician service to the underserved: implications for affirmative action in medical education. Inquiry 1996;33(2):167-80.

9. Kalichman SC, Catz S, Ramachandran B. Barriers to HIV/AIDS treatment and treatment adherence among African-American adults with disadvantaged education. 7 Natl Med Assoc 1999;91(8):439-46.

10. Amonkar MM, Madhavan S. Compliance rates and predictors of cancer screening recommendations among Appalachian women. 7 Health Care Poor Underserved 2002;13(4):443-60.

11. Folsom RC, Widen JE, Vohr BR, Cone-Wesson B, Gorga MP, Sininger YS, et al. Identification of neonatal hearing impairment: recruitment and followup. Ear Hear 2000;21(5):462-70.

12. Zeitlyn S, Rahman AK, Nielsen BH, Gomes M, Kofoed PE, Mahalanabis D Compliance with diphtheria, tetanus, and pertussis immunisation in Bangladesh: factors identifying high risk groups. BM7 1992;304(6827):606-9.

13. Wan J, Greenfield SP, Talley M, Ng M. An analysis of social and economic factors associated with followup of patients with vesicoureteral reflux. $7 \mathrm{Urol}$ 1996;156(2 Pt 2):668-72.

14. McKee MD, Lurio J, Marantz P, Burton W, Mulvihill M. Barriers to followup of abnormal Papanicolaou smears in an urban community health center. Arch Fam Med 1999;8(2):129-34.

15. Amsel S, Boaz M, Ballin A, Filk D, Ore N. Low compliance of iron supplementation in infancy and relation to socioeconomic status in Israel. Pediatrics 2002;110(2 Pt 1):410-1

16. Matthews KA, Kelsey SF, Meilahn EN, Kuller LH, Wing RR. Educational attainment and behavioral and biologic risk factors for coronary heart disease in middle-aged women. Am 7 Epidemiol 1989;129(6):1132-44.

17. Ford ES, Merritt RK, Heath GW, Powell KE, Washburn RA, Kriska A, et al. Physical activity behaviors in lower and higher socioeconomic status populations. Am f Epidemiol 1991;133(12):1246-56.

18. Kaplan GA, Lazarus NB, Cohen RD, Leu DJ. Psychosocial factors in the natural history of physical activity. Am f Prev Med 1991;7(1):12-7.

Correspondence to: James Woo, 87 Nanette Dr., London ON

N5X3L3; jwoo4@uwo.ca 